Bangladesh Journal of Bioethics 2010;1(3):22-34

\title{
STUDY AND ANALYSIS OF STEM CELL THERAPY AND ITS ETHICAL CONSIDERATION
}

\author{
M.Ullah ${ }^{1}$, Vidyanath Chaudhary ${ }^{2}$, Nurul Absar, Ph.D. ${ }^{3}$ \\ 1, 2 Department Of Biochemistry And Biotechnology, University Of Science And Technology Chittagong, \\ (Ustc), Foy's Lake-4202, Bangladesh. \\ ${ }^{3}$ prof. And Head, Department Of Biochemistry And Biotechnology, University Of Science And Technology \\ Chittagong, (Ustc) Foy's Lake-4202, Bangladesh .
}

1Email: babugene11@yahoo.com

\begin{abstract}
The controversy surrounding stem cell research led to an intense debate about ethics. Up until the recent years, the research method mainly focused on Embryonic Stem Cells, which involves taking tissue from an aborted embryo to get proper material to study. This is typically done just days after conception or between the 5th and 9th week. Since then, researchers have moved on to more ethical study methods, such as Induced Pluripotent Stem Cells (iPS). iPS is artificially derived from a non-pluripotent cell, such as adult somatic cells. This is probably an important advancement in stem cell research, since it allows researchers to obtain pluripotent stem cells, which are important in research, without the controversial use of embryos. Nowadays stem cell treatment has been spreaded throughout the world. It has also been grown commercially in developed countries. This paper assesses the stem cell treatment as well as its impact in human life. It also examines specific stem cell therapy market that proves far reaching effect in world economy. Though various organizations have made it as a controversial issue the analysis shows that stem cell treatment has brought positive dimension in human society. A discussion has been made about the ethical issues of stem cell research and therapy; which focus how recent biotechnology and biological understandings of development narrow the debate. It is thought that one day it may be the major key to treat various diseases.
\end{abstract}

Key words: Stem cells, Stem cell treatment, Leukemia, Cardio vascular diseases, Ethical issues, Stem cell therapy business.

Literature search: The paper has been made based on study and analysis of various research papers, articles, books, news on stem cell and stem cell therapy. Here a discussion is made on stem cell and its therapeutic role in human society. Some stem cell treatments are discussed on the basis of case analysis of different experiments on different parts of the world. The demand of stem cell treatments is increasing with time. The analysis seeks to address this issue in this paper. 
Introduction : This study presents the stem cell therapy and its impact in modern society. Nowadays stem cells become a tool for therapeutic purposes. Various types of work are carried out in different parts of the world on the basis of stem cell therapy. Stem cell technology becomes the hope for the patient. Medical researchers believe that stem cell research has ability to dramatically change the approaches to understanding and treating various diseases. Though it has an immense role in the therapeutic purposes, it has some limitation also. Scientists are trying to find out the appropriate solution of those limitation .Some groups considered it as controversial issue. Researchers have already developed the stem cell technology. So its positive site is opened in front of the world. But stem cell is not only enough to develop successful treatment. To develop successful 1 treatment, the importance is on technology and experienced doctor. Stem cell therapy is considered as like a soldier with a weapon. Only if the soldier (experienced doctor), weapon (technology) and bullets (stem cells) all are in our hand than the fight will turn in our favor.

Literature Review : The human body has a variety of 220 different cells types. Stem cells are master cells that act as foundation cells for every organ, tissue and cell in the body. They differ from other cell by their remarkable properties to develop into many different cell types. They are considered as a blank microchip that can be programmed to perform particular tasks. They serve as a repair machine for the body. At present, scientists worked with two broad classes of stem cells from animals and human: embryonic stem cell (isolated from inner cell mass of blastocysts) and non-embryonic "somatic" or "adult" stem cells (Stem cells taken from adult tissue). In 2006, researchers made another breakthrough by identifying new type of stem cell, called induced pluripotent stem cells (iPSCs) thorough genetically reprogramming of specialized adult cell. Last year Jaenisch's group successfully treated transgenic mice carrying the human gene for sickle-cell anemia by giving them hematopoietic stem cells derived from those mice's gene-repaired iPS cells ${ }^{1}$.

Human embryonic stem cells were isolated relatively recently, in 1998. By transplanting cells generated from human embryonic stem cells in to the patient diseases might be treated like Parkinson's disease, diabetes, heart disease, and vision and hearing loss etc. Embryonic stem cells are derived from embryos through fertilization of egg $\underline{\text { in vitro }}$ - in an in vitro fertilization clinic - and then donated for research purposes with informed consent of the donors. They are not derived from eggs fertilized in a woman's body. Now a day human embryonic stem cells are cultured in plastic laboratory culture. Scientists have already established some basic protocols for embryonic stem cells to become some specific cell types.

Adult stem cell also known as somatic (from Greek $\Sigma \omega \mu \alpha \tau$ and germ line (giving rise to gametes) stem cells, they can be found in children, as well as adult ${ }^{2}$.One supply of adult stem cell is from human fetal tissue. The first human stem cells were extracted from "primordial gonadal tissue which was taken from a non-living fetus" ${ }^{3}$.The primary function of adult stem cells_is to maintain and repair the tissue in which they are found. Research on adult stem cells has generated a great excitement. Scientists have found adult stem cells in many more tissues than they once thought possible. This finding 
has led researchers and clinicians to use adult stem cell as therapeutic purposes. Adult stem cells have already produced therapies, while embryonic stem cells have not ${ }^{4,5}$. Moreover, there have been many advances in adult stem cell research, including a recent study where pluripotent adult stem cells were manufactured from differentiated fibroblast by the addition of specific transcription factors ${ }^{6}$.For example bone marrow transplants are a type of adult stem cell therapy. For more than 20 years, patients with leukemia have been treated by introducing hematopoietic (blood forming) stem cells through bone marrow transplantation. Adult stem cells are also used in veterinary medicine to treat tendon and ligament injuries in horse's ${ }^{7}$. The use of these stem cells in research and treatment is not as controversial as embryonic stem cells.

Nowadays Scientists' enthusiasm grows for induced pluripotent cells When Shinya Yamanaka of Kyoto University reported his transformation of cultured mouse skin cells into a state approximating that of embryonic stem cells ${ }^{8}$, he was met with plenty of skepticism. Other scientists hadn't anticipated that such a feat was possible. "Nobody else was even close to doing the same experiment," says Richard Young of the Whitehead Institute in Cambridge, Massachusetts. "That was a very special breakthrough." By inserting just four genes -Oct4, Sox2, Klf4 and Myc- into fibroblasts (cultured skin cells); Yamanaka's group had achieved the biological equivalent of making water flow uphill. The resultant induced pluripotent stem (iPS) cells proliferate indefinitely in culture and differentiate into all the tissues necessary to generate a live mouse ${ }^{9,10}$.

There are lots of advantages and disadvantages in case of adult and embryonic stem cells. Embryonic stem cells are pluripotent, means they are able to form all cell types of the body. On the other hand, adult stem cells do not show the same capabilities. Because they are considered as a tissue-specific stem cell. Rejection is common in embryonic stem cell therapy but it is less of a concern with adult stem cell therapy. This is due to a patient's own cells could be used in culture, a specific cell type produced (differentiation), and finally reintroduced into the patient. The reason of transplant rejection by tissues derived from embryonic stem cell is not clear, since the United States Food and Drug Administration has only recently been approved (FDA). Moreover embryonic stem cells do not participate in the destruction of an embryo but embryonic stem cells have to face this ethical problems. Though both types of stem cells play important role in medical sciences, but there are some limitations to using adult stem cells. Adult stem cells may exhibit DNA abnormality during the course of a lifetime. These potentials might limit the usefulness of adult stem cell in therapy. For this reason, human embryonic stem cells are thought to have much greater developmental potential in comparison to adult stem cells. In 1998, a group led by Dr. James Thomson at the University of Wisconsin developed a technique to isolate and grow the human embryonic stem cells. From then Scientists have completed experiments with human embryonic stem cells. In late January 2009, GeronCalifornia based company get clearance from FDA to begin the first human clinical trial of human embryonic stem cells.

In spite of having some disadvantages, stem cells are used in therapeutic purposes. These activities arise new area in medical technology, called stem cell treatment. Stem cell 
treatments are also familiar as therapy, where new cells are introduced into damaged area to treat a disease or injury in a patient similar to organ transplantation. These treatments are potential enough to change the face of human disease. In medical science, stem cell treatments provide both help and hope to the patients. In May, 2009, Dr. Kameshwar Prasad of the All India Institute of Medical Sciences (AIIMS) gave a presentation on his stem cell study at the European Stroke Research Conference. In his speech he said, "The stem cells had excellent safety profile. After carrying out Pet scans and MRIs thrice in a year on patients who received stem cells, we found no side-effects. This study shows that stem cells are a safe and feasible therapy in acute stroke. This holds promise and needs to be confirmed in a bigger study" ${ }^{11}$.So diseases which can not possible to treat those are treatable and even curable through stem cell treatment.

There are some groups that arise questions about the potentiality of stem cell. There are some obstacles that must be overcome before the potential uses of stem cells in cell therapy .These are - find out stem cell source and provide right conditions to differentiate cells into the specialized cells. The most potential application of human stem cells is the formation of cells and tissues that can be used for cell-based therapy. Researchers are delivering the stem cells intravenously, because they believe the cells naturally migrate to an injury site. Researchers from the Medical College of Georgia (MCG) injected human stem cells $(200,000$ to 400,000$)$ into the brain of animals. The stem cells used in this purpose were multipotent adult progenitor cells. At least 25 percent treated animals shown greater improvement in neurological performance than controls. This result was published by Cesario Borlongan, PhD, a neuroscientist at MCG and the Veterans Affairs Medical Center in Augusta, Ga. The findings are important recovery advances in humans. Researchers think stem cell therapy, aggressive physical therapy and possibly the clotbusting drug tissue plasminogen activator (tPA) decrease the rate of stroke. This is major problem among American adults.

National Institutes of Health stated that: "...there is evidence that adult stem cells may have more limited potential than hPSCs [human pluripotent stem cells]. First, stem cells for all cell and tissue types have not yet been found in the adult human. Significantly, cardiac stem cells or pancreatic islet stem cells have not been identified in adult humans. Second, stem cells in adults are often present in only minute quantities, are difficult to isolate and purify, and their numbers may decrease with age" ${ }^{12}$. On the other hand another group think adult stem cells offer greater potential than originally believed In early 2002, New Scientist magazine reported that Catherine Verfaillie's team at the University of Minnesota had found stem cells in the bone marrow of adults that may be capable of becoming almost any of the 220 tissue types in the human body. These "multipotent adult progenitor cells" or (MAPCs) might match the flexibility and potential of stem cells derived from embryos. Verfaillie's team was able to isolated MAPCs from about 70 of the approximately 100 people who donated samples of their bone marrow ${ }^{13}$.

Stem cells are important because human development occurs from stem cells. Scientists have created many ways of using stem cells to develop into human cells, researchers are confident to treatments many diseases by stem cells - Bone loss, Leukemia, Broken bones, 
Lou Gehrig's disease brain damage due to oxygen starvation, Severe burns, Cancer (some forms), Type 1 diabetes mellitus, Cardiac failure, Hepatitis, Osteoarthritis, incomplete bladder control, Missing teeth, Huntington's, Lupus, Spinal cord injuries ,Muscular dystrophy, Blindness and vision impairment, Multiple sclerosis, Stroke etc .

Leukemia is one of the life threatening diseases in human life. The Leukemia's are neoplastic disorder of hemopoitic tissue where an uncontrolled, abnormal and wide spread proliferation of the leucocytic cells (white blood cells) is occurred. Every year a huge number of people around the world are attacked by these diseases. A common treatment for these diseases is chemotherapy. But it has some problem also. At first most growing cells like leukemia or neoplastic cells are destroyed by the cytotoxic agents, due to chemotherapy. These agents also kill the hematopoietic stem cells within the bone marrow. Unfortunately this side effect arises a question about the use of the chemotherapy. To solve this problem scientists use stem cell as a therapeutic purposes. For over many years bone marrow stem cells have been used by the scientists to treat patients with leukemia and lymphoma. News published in the famous New England Journal of Medicine that stem cells collected from the umbilical cords of newborn babies are viable and valuable transplant source for thousands of leukemia patients who haven't any other treatment option. Every year leukemia patients require a bone marrow transplant, but it is difficult to find out matched relative bone marrow. Umbilical cords are normally discarded after birth can be used to provide real hope for the leukemia patients. Researchers conducted an investigation and comparison of leukemia treatment results in more than five hundred adult patients with stem cells transplant. The research was conducted in the United States during a six-year period ending in 2001, where patient's ages were 16 to 60 years. The Survival rates were maximum (33 percent) for bone marrow transplants with matched unrelated donors. Survival rates were the same (22 percent) for cord blood and one antigenmismatched unrelated bone marrow transplant patients-results that clearly indicate the efficacy of cord blood stem cells when bone marrow donors are unavailable, according to Dr. Laughlin, an Associate Professor of Medicine at Case Western Reserve University School of Medicine ${ }^{14}$. The donated cord blood can be used for any patient for future transplantation. Cord blood transplantation provides stem cell to the patient, help to produce mature blood cells. As comparison to stem cell umbilical cord blood is not controversial; and in fact, it is normally discarded after birth. So new mothers can donate this immediately after delivery. When the doctors cannot find any matching bone marrow, they choice cord blood for their availability. Which is now become the key tool to treat leukemia and other associated diseases. According to Science Daily (June 2, 2004) MAYWOOD, Ill. More than 106,000 people in the U.S. each year are diagnosed with these life threatening diseases.

Various clinical trials have proved adult stem cell therapy is safe and effective to treat heart disease. This therapy is available for heart disease on at least five continents. For example, now it is possible to generate healthy heart muscle cells in the laboratory and then transplant into patients with chronic heart disease. In preliminary research of transplantation of bone marrow stromal cells in damaged heart of mice and other animals indicates beneficial effects. Cardiovascular disease (CVD) includes coronary heart disease, 
congestive heart failure, hypertension, and stroke. Cardiovascular disease is a leading cause of death worldwide killing 17 million people each year ${ }^{15}$, especially due to heart attack and stroke. In the United States, heart disease is the number one cause of death. The high rate of mortality associated with heart diseases is the inability to repair damaged tissue ${ }^{16}$. Therefore a potentially new strategy to treat heart failure is restoring damaged heart muscle tissue, through repair or regeneration .The use of adult and embryonic stem cells for cardiac repair is a dynamic area of research. The umbilical cord blood cells have also been investigated as possible sources for regenerating damaged heart tissue. A recent report used a swine model of atrioventricular block and transplanted human ES cellderived cardiomyocytes into the pig's heart to work as a pacemaker ${ }^{17}$. The ES cells survived, functioned and integrated well with the host cells. A new research on stem cell shows that partial paralysis of stroke patients can be cured by a person's own adult stem cells. For example a stem cell study took place in New Delhi, India, there 12 stroke patients were treated with their own stem cells within 1 month after a stroke. As a control group 3 stroke patients were used without stem cell transplantation. However after year, $70 \%$ ( 7 or 8 of the patients) were able to overcome their handicaps and successfully return to their normal life .Only 1 out of the 3 in the control group were able to go back to their normal routine. There was no side effects from own stem cells transplantation. Another study shown that transplantation of embryonic stem cells to mouse embryos in the earliest stages of development demonstrated a capacity to recover from cardiac injury in adulthood. This study provides the first regenerative medicine can successfully treat myocardial infarction through prophylactic intervention.

Eye is the important organs in human life. There are many reasons for blindness and vision impairment .But these are not curable by current medical technology. Stem cells also play a vital role in this field. Researchers have already transplanted human retinal stem cells to restore vision into damaged eyes. Scientists grown a totipotent stem cells in the laboratory and then transplanted this sheet over the damaged retina, this stem cells stimulate repair mechanism, eventually restoring vision. The latest such development was in June 2005, when researchers at the Queen Victoria Hospital of Sussex, England were able to restore the sight of forty patients using the same technique. The group, led by Dr. Sheraz Daya, was able to successfully use adult stem cells obtained from the patient, a relative, or even a cadaver. Further rounds of trials are ongoing ${ }^{18}$. Moreover The University Hospital of New Jersey claims a success rate growing the new cells from transplanted stem cells varies from 25 percent to 70 percent ${ }^{19}$. A degenerative disease called keratoconus which causes vision impairment arises due to corneal transplants and has no known cure. Researcher hoped that one day stem cell research will provide a treatment to such devastating corneal disorders.

Stem cells are also used in the treatment of Multiple sclerosis (MS), an autoimmune disease that affects about 85,000 people in the UK. Dr Doug Brown, research manager at the MS Society, said, "Stem cells are showing more and more potential in the treatment of MS and the challenge we now face is proving their effectiveness in trials involving large numbers of people" ${ }^{20}$. A clinical trial investigating the treatment of patients with multiple sclerosis (MS) using bone marrow stem cells has produced encouraging results, researchers at Bristol University have reported. In the phase I clinical trial, six MS patients were 
injected with stem cells harvested from their own bone marrow. The main aim of the study was to determine whether this procedure was safe and free from side effects. The study, carried out at Frenchay Hospital, found no serious side effects associated with the procedure. It also found that the MS was stable in five out of the six patients receiving bone marrow stem cells, and did not deteriorate over the twelve month period. Dr Claire Rice, Research Fellow at the University of Bristol, said: 'The results are very encouraging. We would have expected these pathways to get worse but they have actually got better. It is exciting because the treatment is relatively pain free and patients do not need to stay overnight in hospital' ${ }^{21}$.

Scientists in Berlin "Cure" Patient of HIV Disease is supported by a report published in The New England Journal of Medicine in February of 2009. In this report, Berlin doctors describe a male patient who has both HIV infection and leukemia. In order to treat this patient's leukemia, doctors transplanted stem cells from a donor who was naturally resistant to the HIV virus. Such naturally resistant people to the HIV virus comprise approximately $1 \%$ of the general population and are deemed such as they have a genetic mutation of the CCR5 gene which is required for susceptibility to HIV infection. After the stem cell transplant for the patient's leukemia was performed with the HIV resistant cells, the patient was able to discontinue taking all anti-HIV medications and remained without detectable HIV virus in his blood for the 20 consecutive months he was monitored. In effect, this patient was "cured" of his HIV disease ${ }^{22}$.

Besides this stem cell also replace missing teeth. In theory, stem cells taken from the patient could be coaxed in the lab into turning into a tooth bud which, when implanted in the gums, will give rise to a new tooth, which would be expected to take two months to grow ${ }^{23}$. Researcher are trying to use stem cell treatment in Parkinson's disease which is the second neurodegenerative disease following Alzheimer's. Approximately 1.5 million people in the United States suffer from Parkinson's disease ${ }^{24}$. Another focusing site of stem sell transplant is in veterinary animals .Research currently conducted on horses, dogs, and cats can benefit the development of stem - cell treatments in veterinary medicine, but may also contribute to developing those in human medicine for a range injuries and diseases such as myocardial infarction, stroke, tendon and ligament damage, osteoarthritis, osteochondrosis and muscular dystrophy ${ }^{25,26,27,28}$.

Though stem cell therapy plays remarkable role in medical science it has also some limitation. Adult stem cells are not yet a permanent solution for diseases. It is difficult to judge its therapeutic potential. Some patients show a noticeable improvement after treatment with these stem cells, but the same treatment will have no effect on others patient. So more research is needed on this field.

Ethical issues: Now a day's ethics is the important topics in case of biological research. Stem cell research is monitored by various groups. They have raised their voice against stem cell research. Though embryonic stem cells have greater plasticity, potentially 
allowing them to treat a wider range of diseases ${ }^{29}$. But in recent years human embryonic stem cell research is controversial because, to create a stem cell line a human embryo has to destroy. Opponents of stem cell research also say this technology devalue human life. Many pro-lifers like Roman Catholics and conservative Protestants raised their vice against Embryonic Stem Cell Research (ESCR). They claim that embryo is human being. During stem cell extraction, the embryos are killed. They compare the method as murder of human. If the basis for protecting embryos is that they have the potential to become reasoning beings, then, some argue, we have reason to ascribe a high moral status to the trillions of cells that share this potential and to assist as many of these cells as we reasonably can to realize their potential (Sagan \& Singer 2007, Savulescu 1999). But it is morally permissible to kill an individual who is about to be killed by someone else where killing that individual will help others (Curzer, H. 2004) ${ }^{30}$. On the other hand researcher proved that stem cells are unable to grow in to a complete person except an organ. So stem cell cannot create a human life. Some parties contend that embryos are not humans, believing that the life of Homo sapiens only begins when the heartbeat develops, which is during the 5 th week of pregnancy ${ }^{31}$, or when the brain begins developing activity, which has been detected at 54 days after conception ${ }^{32}$. Moreover in many countries abortions are legal. So a logical argument is why not using them for stem cell research or treatments? The US government has declared embryonic stem cell research legal in this year. This order will give motion in embryonic stem cell research. The importance of embryonic stem cell research can be understood from President Barack Obama speech. In a speech before signing the executive order, President Obama noted the following: "Today, with the Executive Order I am about to sign, we will bring the change that so many scientists and researchers; doctors and innovators; patients and loved ones have hoped for, and fought for, these past eight years: we will lift the ban on federal funding for promising embryonic stem cell research. We will vigorously support scientists who pursue this research. And we will aim for America to lead the world in the discoveries it one day may yield" 33 . By executive order on March 9, 2009, President Barack Obama removed certain restrictions on federal funding for research involving new lines of human embryonic stem cells. Not onlyin U.S.A but also other developed countries take initiative step about stem cell research.They make different types of law to control the stem cell researchfor their country. Austria, Denmark, France, Germany, and Ireland do not allow the production of embryonic stem cell lines, the creation of embryonic stem cell lines is permitted in Finland, Greece, the Netherlands, Sweden, and the United Kingdom ${ }^{34}$. According to a January 9,2007 Daily Telegraph (London) article reporting on a statement by Dr. Anthony Atala of Wake Forest University, the fluid surrounding the fetus has been found to contain stem cells that, when utilized correctly, "can be differentiated towards cell types such as fat, bone, muscle, blood vessel, nerve and liver cells", according to the article. The extraction of this fluid is not thought to harm the fetus in any way. "Our hope is that these cells will provide a valuable resource for tissue repair and for engineered organs as well," said Dr Atala ${ }^{35}$. The developed countries also involved in embryonic stem cell research. In 23 January 2009 - The United States Food and Drug Administration approves clinical trials for human embryonic stem cell therapy ${ }^{36}$. In case of extraction of adult stem cells there are 
no major ethical concerns. Bioethicist Dr. Nigel Cameron said, "We know that adult stem cells, which have no ethical problem, can do the job, as well" ${ }^{37}$.

However, recently it has been shown in principle that adult stem cell lines can be manipulated to generate embryonic - like stem cell lines using a single-cell biopsy similar to that used in preimplantation genetic diagnosis that may allow stem cell creation without embryonic destruction ${ }^{38}$. It can be said easily stem cells have a huge promise to help mankind. It saves life and cure diseases. This creates a very strong moral demand to explore their potential. Stem cell therapy business is becoming a key factor in economy in developed countries. In U.S.A this business is increasing day by day. This is shown in following chart:

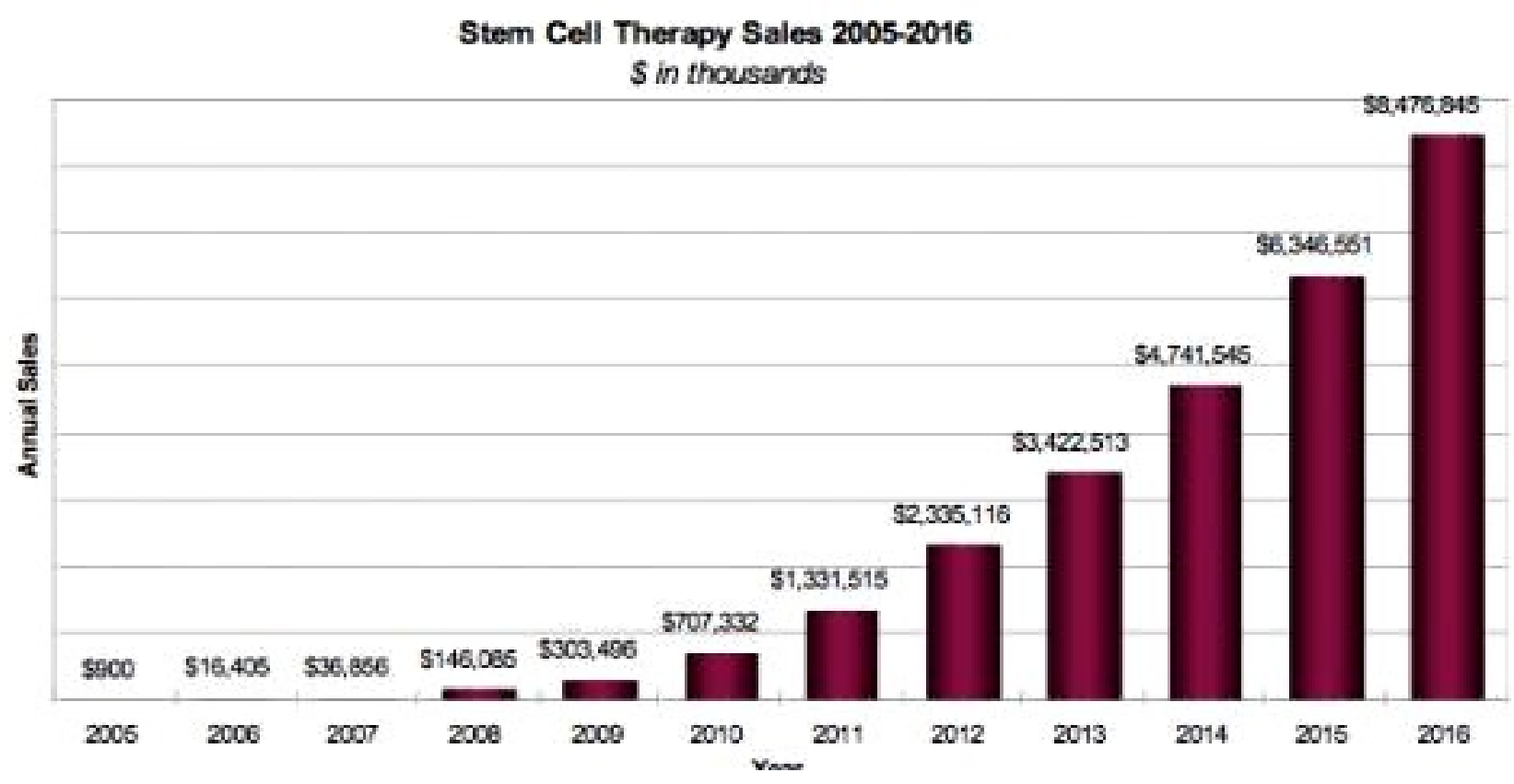

Fig : Stem Cell Market Analysis Fact Sheet of the 2nd Annual Stem Cell Summit, February 12-13 at San Diego ${ }^{39}$,

On the above chart it has been shown clearly that stem cell therapy business has far reaching effect in U.S.A. economy.

Result and discussion: At present creating a new stem cell line for mammals is difficult; for primates including humans it is particularly difficult. In spite of that stem cells treatment has shown a hope for the patient. In future it may be the key tools for treating various diseases .Future stem cells study could also increase our knowledge about abnormal cell division and differentiation, which causes cancer and birth defects. However, iPS (induced pluripotent stem cells) will maybe be the wave of the future. They have various similar properties as embryonic stem cells. News was published in the Healthy Day news paper in April 23, 2009 that scientists have already converted adult cells into 
embryonic-like stem cells by using chemical programming. This may permit adult stem cells to work as embryonic stem cells without significant ethical concerns. Stem cell acts as a renewable source of replacement cells and tissues. This would greatly diminish the risk of rejection in any form of transplant operation. For unique properties, stem cell therapy is important for today's medical technology. Through research on this topic it is found that there is a significant mis-information about the stem cell research because some opponents of stem cell research are misguiding the public for their own political agendas. There exists a social and scientific uncertainty about stem cell research, which could possibly be overcome through future study, and further education of the public. By allowing research and increasing funding the public will be informed more accurately and the true benefits of stem cells research will be more clearly realized. And that will make stem cell more beneficial for mankind.

\section{References}

1. Hanna, J. et al. Treatment of sickle cell anemia mouse model with iPS cells generated from autologous skin. Science 318, 1920-1923 (2008).

2. Jiang Y, Jahagirdar BN, Reinhardt RL, et al (2002). "Pluripotency of mesenchymal stem cells derived from adult marrow". Nature 418 (6893): 41-9. Doi: 10.1038/nature00870. PMID 12077603 .

3. Anon, "Human Embryo research/fetal experimentation," Focus on the Family, Policy statement dated 1997-DEC-15.See:http://www.family.org/

4. Clarke, Michael F. and Michael W. Becker. (July 2006). "Stem Cells: The Real Culprits in Cancer?" Scientific American. Retrieved on August 8, 2006.

5. Anonymous (September 24, 2006) "Cloning/Embryonic Stem Cells." National Human Genome Research Institute. Retrieved September 24, 2006.

6. Cyranoski. "Simple switch turns cells embryonic". Nature 6 June 2007.

7. Kane, Ed (2008-05-01). "Stem-cell therapy shows promise for horse soft-tissue injury, disease". DVM Newsmagazine. http://www.dvmnews.com/dvm/Equine+Medicine/Stemcell-therapy-shows-promise-for-horse-soft-

tis/ArticleStandard/Article/detail/515503.Retrieved on 2008-06-1.

8. Takahashi, K. \& Yamanaka, S. Induction of pluripotent stem cells from mouse embryonic and adult fibroblast cultures by defined factors. Cell 126, 663-676 (2006). | Article | PubMed | ISI | ChemPort | 
9. Okita K., Ichisaka, T. \& Yamanaka, S. Generation of germ line-competent induced pluripotent stem cells. Nature 448, 313-318 (2007). | Article | PubMed | ISI | ChemPort |

10. Wernig, M. et al. In vitro reprogramming of fibroblasts into a pluripotent ES-cell-like state. Nature 448, 318-324 (2007). | Article | PubMed | ISI | ChemPort |

11. repairstemcell.wordpress.com/2009/04/20/ Stem Cell Research Shows Adult Stem Cells Help Stroke Victims Posted 20 April, 2009 in Stroke |

12. National Institutes of Health guidelines for research using human pluripotent stem cells," at: http://www.nih.gov/ .

13. Sylvia Pagan Westphal, "Is this the cell that could revolutionize medicine?" 2002-JAN26, New Scientist (http://www.newscientist.com) Online at: http://www.eurekalert.org/

14. University Hospitals of Cleveland (2004, November 30). Leukemia Patients Survive With Stem Cell Transplant. Science Daily. Retrieved April 16, 2009, from http://www.sciencedaily.com /releases/2004/11/041129112109.htm

15. http://www.who.int/cardiovascular_diseases/resources/atlas/en/.

16. Jackson, K.A., Goodell, M.A. (2004) Generation and Stem Cell Repair of Cardiac Tissue. Stem Cell Handbook, edited by Sell, S. 259-266.]

17. Kehat, I., Khimovich, L., Caspi, O., Gepstein, A., Shofti, R., Arbel, G., Huber, I., Satin, J., Itskovitz-Eldor, J., Gepstein, L. (2004) Electromechanical Integration of Cardiomyocytes Derived from Human Embryonic Stem Cells . Nature Biotechnol. 22, 1282-1289.

18. BBC NEWS | England | Southern Counties | Stem cells used to restore vision .

19. The University Hospital of New Jersey, 2002.

20. http://news.bbc.co.uk/2/hi/health/7858559.

21. Rachael Panizzo-Multiple Sclerosis stem cell therapy trialed. BioNews 557 (10 May 2010) http://www.bionews.org.uk/page_59801.asp

22. Robert Maietta, MD.Can Stem Cell Therapy Cure HIV and AIDS? www.suite101.com/content/can-stem-cell-therapy-cure-hiv-and-aids-a201245

23. Teeth from scratch .

24. www.parkinson.org/site/pp.asp?c=9dJFJLPwB\&b=71125. 
25. Chen J, Li Y, Wang L, Zhang Z, Lu D, Lu M, Chopp M. Therapeutic benefit of intravenous administration of bone marrow stromal cells after cerebral ischemia in rats. Stroke. 2001; 32: 100

26. Assmus B, Schachinger V, Teupe C, et al. Transplantation of Progenitor Cells and Regeneration Enhancement in Acute Myocardial Infarction (TOPCARE-AMI). Circulation 2002 Dec 10; 106(24):3009-17

27. Murphy JM, Fink DJ, Hunziker EB, Barry FP. Stem cell therapy in a caprine model of osteoarthritis. Arthritis Rheum 2003 Dec; 48(12):3464-74

28. Sampaolesi $\mathrm{M}$, et al. Mesoangioblast stem cells ameliorate muscle function in dystrophic dogs. Nature. 2006: 444:574-579.

29. "Arguments For Stem cell Research". Spinney press. 2006. http://web.archive.org/web/20080201224807/http://www.spinneypress.comau/178_book_d esc.html.Retrieved on 2007-12-26

30. Ethics of Stem Cell Research. Stanford Encyclopedia of Philosophy. Fri Apr 25, 2008

31. Greenfield, Marjorie. "Dr. Spock.com".Retrieved 2007-01-20.

32. Singer, Peter. Rethinking life \& death: the collapse of our traditional ethics, page 104 (St. Martins Press 1996). Retrieved 2007-03-04

33. A debt of gratitude to so many tireless advocates.

34. As noted before, the production of hESC lines is currently illegal in Germany; the 1990 Embryo Protection Act prohibits any utilization of the embryo that does not serve its preservation. ... Ireland, Austria, Denmark and France prohibit any production of hESC lines...Finland, Greece, the Netherlands, Sweden and the UK allows the production of hESC lines from surplus IVF embryos."Peter M. Wiedemann, Judith Simon, Silke Schicktanz \& Christof Tannert (2004). "The future of stem-cell research in Germany". Nature and the European Molecular Biology Organization.

35. Clout, Laura; and Agencies (2007-09-01). "'Scientists report alternative stem cell source"'". DailyTelegraph(UK).http://www.telegraph.co.uk/news/main.jhtml? $\mathrm{xml}=/$ news/2007/01/08/ustem108.xml.Retrieved on 2007-09-20

36. "Green light for US stem cell work". BBC News. http://news.bbc.co.uk/2/hi/health/7847450.stm

37. Steve Jordahl, "Calif. Governor Signs Stem Cell Bill," at: http://www.family.org/ 
38. Nell Greenfieldboyce (23 August 2006). "Firm creates stem cells without hurting embryos".National Public Radio. http://www.npr.org/templates/story/story.php? storyId $=5696557$.

39. Pimm.wordpress.com Posted by attilachordash on February 13, 2007. 